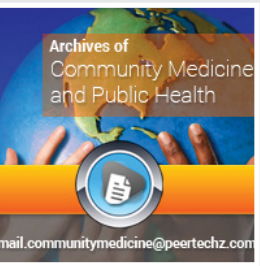

\title{
Archives of Community Medicine and Public Health
}

Sumanth Mallikarjuna Majgi'*, Purushottam A. Giri ${ }^{2}$ and Bhavani Nivetha $^{3}$

'Asst. Professor, 3Postgraduate Student, Dept. of Community Medicine, Mysore Medical College \& Research Institute, Mysore, Karnataka, India ${ }^{2}$ Professor, Dept. of Community Medicine, IIMSR Medical College, Badnapur, Jalna, Maharashtra, India

Dates: Received: 24 August, 2017; Accepted: 21 September, 2017; Published: 23 September, 2017

*Corresponding author: Dr. Sumanth Mallikarjuna Majgi, Assistant Professor, Department of Community Medicine, Mysore Medical College \& Research Institute, Mysore, Karnataka, India;

E-mail: drsumanthmmc@rediffmail.com

Keywords: Non-communicable diseases (NCDs), Tertiary care hospitals, Life style diseases

https://www.peertechz.com

\section{Short Communication}

Don't We Need Non-communicable Diseases Block in Government Tertiary Care Hospitals?

\section{Abstract}

Non-communicable Diseases (NCDs) are emerging as the major cause of morbidity and mortality globally. In India, non-communicable diseases (NCDs) contribute to around 5.87 million deaths that account for $60 \%$ of all deaths. India shares more than two-third of the total deaths due to NCDs in the South-East Asia Region. World Health Assembly endorsed the WHO Global Action Plan for the Prevention and Control of NCDs for 2013-2020, the goal is to reduce the preventable and avoidable burden of morbidity, mortality and disability due to non-communicable diseases by means of multi-sectoral collaboration and cooperation at national, regional and global level. When analyzed about the existing health care services in India, the primary health centers are the first point of contact for a patient with the health care, the services provided in the primary Health centers are grossly inadequate, in India almost $40 \%$ of the primary health centers are functioning without lab technician and $9 \%$ without doctors. In order to improve the NCD services in a tertiary care, we have to address the issue of dissatisfaction in patients in tertiary care by providing a better organized service which will lead to better compliance of the patient to treatment.

\section{Introduction}

Non-communicable Diseases (NCDs) are emerging as the major cause of morbidity and mortality globally. They are of long duration and generally slow progression. These diseases also need frequent monitoring and hence naturally require periodic doctor visit. The 4 main types of non-communicable diseases are cardiovascular diseases (like heart attacks and stroke), cancers, chronic respiratory diseases (such as chronic obstructive pulmonary disease and asthma) and diabetes. These 4 groups of diseases account for $82 \%$ of all NCD deaths. According to 2012 report, Non-communicable diseases (NCDs) kill 38 million people each year i.e. $68 \%$ of world's total death. Almost three quarters of NCD deaths - 28 million - occur in low- and middle-income countries. Sixteen million NCD deaths occur before the age of 70. Cardiovascular diseases account for most NCD deaths, or 17.5 million people annually, followed by cancers ( 8.2 million), respiratory diseases ( 4 million), and diabetes (1.5 million) [1].

In India, non-communicable diseases (NCDs) contribute to around 5.87 million deaths that account for $60 \%$ of all deaths. India shares more than two-third of the total deaths due to NCDs in the South-East Asia Region (SEAR) of WHO [2]. The country is experiencing an epidemiological transition from infectious to chronic diseases with over $20 \%$ of the population in India having at least one chronic disease and more than $10 \%$ have more than one. Given the magnitude and complexity of the NCD burden, the central point of India's future health strategy should be the formation of an evidence-based action plan for the government and private sector towards achieving superior healthcare outcomes [3]. World Health Assembly endorsed the WHO Global Action Plan for the Prevention and Control of NCDs for 2013-2020, the goal is to reduce the preventable and avoidable burden of morbidity, mortality and disability due to non-communicable diseases by means of multi-sectoral collaboration and cooperation at national, regional and global level. WHO provides a road map and menu of policy options which when implemented will contribute to progress on 9 global NCD targets to be attained by 2025 [4].

Patients with NCD's require a comprehensive treatment plan delivered by a multi-disciplinary health professional team. Hence, a patient-centric approach rather than a disease centric is the need of the hour. Integrated treatment and management guidelines should be formed outlining the best practices in prevention and chronic-care programs [3].

When analyzed about the existing health care services in India, the primary health centres are the first point of contact for a patient with the health care, the services provided in the primary Health centres are grossly inadequate, in India almost 
$40 \%$ of the primary health centres are functioning without lab technician and $9 \%$ without doctors [5]. In a study conducted by Pakhare A et al on Assessment of primary care facilities for cardiovascular disease preparedness in Madhya Pradesh, India, It was concluded that with respect to availability of services it was least in laboratory services, and human resource domains followed by drugs, and better in equipment and point-of-care supply domains. Across these domains, availability of items in CHCs were (37.1, 49.0, 56.1, 67.9 and $80.9 \%$ respectively) and in PHCs (11.8, 18.2, 44.2, 55.1, and 55.3\% respectively). From the above study it is evident that the NCD services are not upto the mark in PHC's [6].

Of the Global targets to be achieved according to global action plan drug availability is of paramount importance, At least $50 \%$ of eligible people should receive drug therapy and counselling (including glycemic control) to prevent heart attacks and strokes. An $80 \%$ availability of the affordable basic technologies and essential medicines, including generics, required to treat major non-communicable diseases in both public and private facilities [4]. The study clearly points out that in PHC's the basic technology and drug availability is grossly poor at $11.8 \%$ and $44.2 \%$ respectively.

Since the quality of services in the primary center is inadequate in India people predominantly prefer the private health facilities. In a study conducted by IMS Institute for Healthcare Informatics [4], in over 14,000 households across 12 states (including urban and rural areas). There has been a steady increase in the usage of private healthcare facilities over the last 25 years for both Out Patient and In Patient services, across rural and urban areas. In 1986 - 1987, the choice for patients in both rural and urban centers was tilted in favor of public hospitals over private hospitals ( 60 to $40 \%$ ). In $2012,61 \%$ in urban areas had chosen the private sector over the public, and in rural areas, nearly $69 \%$ had put their faith in the private sector. The primary reason, the study goes on to prove, is the long waiting time, absence of doctors, and a dis-satisfaction with quality standards at public hospitals. However, it did add that between 85 and $90 \%$ of the patients are willing to shift from the private sector if the situation improved in the public health care facilities [7]. In another study by Bhattacharyya D et al. [8], to identify the factors associated with utilization of healthcare for non-communicable diseases in southern part of India they concluded that the factors waiting time, distance to health center, income, education and health insurance were statistically significant $(\mathrm{p}<0.05)$. Also found that $60 \%$ patients preferred private facilities. It is evident from the above studies that people prefer private facilities for quality and less wait time.

However, in a 18-month long survey conducted by PGIMER, Chandigarh, in which 5127 respondents participated from 22 districts of Punjab, it was concluded that a Person suffering from non-communicable disease in Punjab spends Rs. 1,100/a month, Those who need hospitalization spend an average additional amount of Rs. 12,000/-, apart from their monthly medical expenses. It has also revealed that an individual with NCDs has to suffer indirect cost as well in terms of hours lost in the process of travelling to and waiting at hospitals. The survey has found that in a month, a visit to a health facility averages out to about 10 hours travel time, plus waiting time at the hospitals and higher proportion of people visit private hospitals than public health centers/hospitals in rural areas. The survey has pointed that out of the total amount spent on availing Out Patient Department (OPD) consultation, highest amount was spent on drugs (49\%) followed by diagnostic tests (23 percent) [9]. Though the quality of services in private facility is good, as the above study has pointed out the financial burden on the patient is too high so the last resort for people is government tertiary care hospitals. In a country where there is tremendous shortfall of healthcare delivery at the periphery level the load on the tertiary care hospital has become mighty and almost impossible to handle. One of the many problems plaguing India's public hospital is overcrowding. In the nation's highest respected institution, All India Institute of Medical Sciences at New Delhi the daily patient load at OPD comes to around 10000 [3]. Of these approximately at least $20 \%$ will be a chronic disease patient. India which has acquired the label of "an ageing nation" with $7.7 \%$ of its population being more than 60 years old [10]. The majority of the OPD patient consists of elderly people battling the effects of ageing with no one to support them both psychologically and financially These people after standing in queues for long hours awaiting their turn, when they finally get to the doctor they will be asked to go for further tests and get opinion from cardiology, ophthalmology departments, asking a person to go to few more places to avail the health care needs for which he has been standing for hours is really unfair. Not to mention the physical and mental stress we put them in, as anyone who has visited a government tertiary hospital can tell us how difficult it is to find the different sections. Even a well-educated person with the help of all the sign boards finds it difficult to figure out the route. If we go inside the government tertiary care and just stand in a single place for few minutes you will encounter at least 2 to 3 patients who have lost their way trying to figure out where to go. Particularly for chronic diseases for which the patient visits should be frequent, dreading the above circumstances they refuse to come for follow up. So at the primary level lack of resources, at tertiary level overloading and lack of follow up and at the private facility the financial burden are blocking the provision of quality NCD services. One may argue that not all patients are in same situation, more than half of the OPD patients in government hospitals are facing one or the other difficulty. The health care provided should be according to the needs of the population; if they are subjected to such difficulties and hurdles in seeking the health care then whatever programme we implement to tackle these NCD's it won't reach the population.

Study by Saini NK et al. [11], conducted a comparative assessment of satisfaction among Outpatient Department patients visiting secondary and tertiary level Government hospitals of a District in Delhi on 400 outpatients concluded that in the secondary hospital, $76.1 \%$ respondents termed the hospital services as satisfactory, $78.8 \%$ were satisfied with the treatment given, $78.5 \%$ stated that the services provided were worth the money spent, and $94.5 \%$ replied that they would like 
to visit the facility again in case the need arose, while the same proportion was $36.8,32.8,24.0$, and $16.9 \%$ respectively. The reason for the above perception of people as secondary center is satisfactory than tertiary center can be due to less waiting time, lesser distance roamed about, more time spent by physician with the patient. So it is clear from the above study that in spite of providing advanced care, secondary centers are giving better satisfaction for the patients than tertiary centers. In order to improve the NCD services in a tertiary care, we have to address the issue of dissatisfaction in patients in tertiary care by providing a better organized service which will lead to better compliance of the patient to treatment.

\section{Conclusion and Recommendations}

It is need of the hour to bring about innovative changes in the tertiary care services particularly for non-communicable diseases. A large majority of load in general OPD can be reduced if separate Non-communicable disease block with an OPD is established. This block should provide comprehensive integrated services. The process should start at the administrative and policy making level. It needs an extraordinary political will and strategic involvement of stake holders. The block planning and financial facilities should be provided directly from the National programme for prevention and control of Diabetes, Cardiovascular disease and stroke. Just like how separate antiretroviral therapy center establishment has improved the compliance of the patients to treatment and has provided a better quality of life to HIV positive people, If individual attention and better drug availability are given the treatment and Follow up of NCD's will reach great heights. Basically the NCD services should be delinked from the general OPD and a multidimensional approach towards the management should be done.

The departments of Public health, ophthalmology, cardiology, nephrology and neurology should be integrated and established under a single roof. A faculty from each department should be posted their along with interns. The screening of patients and counseling sessions will be carried out by a public health specialist, Ophthalmology department will screen for retinal changes in diabetic and hypertensive patients, Cardiology will carry out the follow up of Cardiovascular patients and also will screen for complications in diabetes and hypertension, Nephrology will also screen for complications in diabetes and hypertension, Neurology will carry out the follow up for the stroke patients and screen for neurological complications in diabetics. A separate dressing room for diabetic wound care management with a staff nurse should be established.
There should be an attached laboratory just to carry out the NCD investigations. A pharmacy should be set up in the block to supply the essential NCD drugs. The investigations and drugs should be supplied free of cost. If the health care is provided under a single place the wait time of the patient and roaming about is reduced. Hence they will be appealed to avail these services and regular follow-up for complications can be done effectively. This will also in-turn lead to reduction in the other OPD patient load so each department can spend more time in treating patients belonging to their specialization. If properly planned and established with extraordinary political will India can lead the world in NCD management. Like the great Martin Luther King Said once "Of all the forms of inequality, injustice in health care is the most shocking and inhumane." People are entitled to equal and quality care let's take the first step in Bringing about a change.

\section{References}

1. (2016) Non-communicable diseases media centre factsheet. WHO [serial online] [cited 2017 Feb 01]; [6 screens]. Link: https://goo.gl/5Tky8r

2. (2014) Burden of NCDs and their risk factors in India (Excerpted from Global Status Report on NCDs -2014). Link: https://goo.gl/kTuzsi

3. Dhaor A (2015) With over 10,000 OPD patients, many die waiting at crowded AlIMS. Hindustan times 2015 Jul 09. Link: https://goo.gl/bpgL3K

4. (2013) Global action plan for the prevention and control of non-communicable diseases. World Health Organization 2013. Link: https://goo.gl/soQDVz

5. (2014) Rural health statistics. Government of India, Ministry of Health and Family Welfare [serial online] 2014 [cited 2017 Feb 02]. Link: https://goo.gl/9mWv8G

6. Pakhare A, Kumar S, Goyal S, Joshi R (2015) Assessment of primary care facilities for cardiovascular disease preparedness in Madhya Pradesh, India. BMC Health Services Research 15: 408. Link: https://goo.gl/wJCCJS

7. (2013) Understanding Healthcare Access in India. Report by the IMS Institute for Healthcare Informatics. Link: https://goo.gl/nWPzUo

8. Bhattacharyya D, Pattanshetty SM, Duttagupta C (2017) A cross-sectional study to identify the factors associated with utilization of healthcare for non-communicable diseases in a southern part of India. Int J Med Sci Public Health 6: 96-101. Link: https://goo.gl/AiWUvK

9. Akhzer A (2015) PGIMER survey: 'Person suffering from non-communicable disease in Punjab spends Rs. 1,100/- month'. The Indian Express 25 Dec 2015. Link: https://goo.gl/rfbmbV

10. Ingle GK, Nath A (2008) Geriatric health in India: Concerns and solution. Indian J Community Med 33: 214-218. Link: https://goo.gl/4PMmBs

11. Saini NK, Singh S, Parasuraman G, Rajauora OP (2013) Comparative Assessment of Satisfaction Among Outpatient Department Patients Visiting Secondary and Tertiary Level Government Hospitals of a District in Delhi. Indian J Community Med 38: 114-117. Link: https://goo.gl/mBqDgD 